\title{
Rural Emergency Nurses' End-of-Life Care Obstacle Experiences: Stories from the Last Frontier
}

\author{
Renea L. Beckstrand \\ Brigham Young University - Provo \\ Jonathan Rohwer \\ Karlen E. Luthy \\ Brigham Young University - Provo \\ Janelle L. B. Macintosh \\ Brigham Young University - Provo, janelle-macintosh@byu.edu \\ Ryan J. Rasmussen \\ Brigham Young University - Provo \\ Follow this and additional works at: https://scholarsarchive.byu.edu/facpub \\ Part of the Other Nursing Commons
}

\section{Original Publication Citation}

Beckstrand, R. L., Rohwer, J. ${ }^{\star \star}$, Luthy, K. E., \& Macintosh, J. L. B., Rasmussen, R. J. (2017). Rural emergency nurses' end-of-life care obstacle experiences: Stories from the last frontier. Journal of Emergency Nursing, 43(1), 40-48.

\section{BYU ScholarsArchive Citation}

Beckstrand, Renea L.; Rohwer, Jonathan; Luthy, Karlen E.; Macintosh, Janelle L. B.; and Rasmussen, Ryan J., "Rural Emergency Nurses' End-of-Life Care Obstacle Experiences: Stories from the Last Frontier" (2015). Faculty Publications. 5203.

https://scholarsarchive.byu.edu/facpub/5203

This Peer-Reviewed Article is brought to you for free and open access by BYU ScholarsArchive. It has been accepted for inclusion in Faculty Publications by an authorized administrator of BYU ScholarsArchive. For more information, please contact ellen_amatangelo@byu.edu. 


\title{
Rural EMERGENCy NurSes' END-OF-LifE Drossmatk Care Obstacle EXPERIEnCES: STORIES From THE LAST FRONTIER
}

\author{
Authors: Renea L. Beckstrand, PhD, RN, CCRN, Jonathan Rohwer, MS, FNP-c, Karlen E. Luthy, DNP, \\ Janelle L.B. Macintosh, PhD, and Ryan J. Rasmussen, MSN-FNP, Provo, UT
}

\section{CE Earn Up to 6.0 CE Hours. See page 90.}

Introduction: Rural emergency nurses face unique obstacles to providing quality end-of-life (EOL) care. Stories provided by emergency nurses embody their most difficult EOL care obstacles.

Methods: A questionnaire was sent to 53 rural hospitals. Respondents were asked to share stories that epitomized the obstacles faced while providing EOL care in the rural emergency setting.

Results: The lack of an ideal death (eg, the nurse personally knows the patient, issues with family members, and unknown patient wishes) was the top obstacle. Other reported obstacles were insufficient ED staff and power struggles between nurses and physicians.
Discussion: Rural emergency nurses often provide EOL care to friends and family members, whereas their urban counterparts are likely to transfer care to nurses with no relation to the dying patient. Not only does caring for patients whom the nurse knows or is related to cause great distress to rural emergency nurses, but this unfortunately common situation also may prevent patients from receiving the highest quality EOL care.

Key words: Emergency; End of life; Obstacles; Emergency nurse; Rural; Rural nursing
W hen a patient dies in the emergency department, emergency nurses play a significant role in providing bedside end-of-life (EOL) care. Administering EOL care in a compassionate and professional manner can be one of the most stressful and difficult facets of nursing care. ${ }^{1}$ Whereas maintaining the highest level of comfort possible for the patient and family can be difficult under the best conditions, providing comfort

Renea L. Beckstrand is Professor, College of Nursing, Brigham Young University, Provo, UT.

Jonathan Rohwer is FNP Student, Lakeside Medical, Salt Lake City, UT.

Karlen E. Luthy is Assistant Professor, College of Nursing, Brigham Young University, Provo, UT.

Janelle L. B. Macintosh is Assistant Professor, College of Nursing, Brigham Young University, Provo, UT.

Ryan J. Rasmussen is Assistant Teaching Professor, College of Nursing, Brigham Young University, Provo, UT.

This study was funded through a research grant from Brigham Young University College of Nursing, Provo, UT.

For correspondence, write: Renea L. Beckstrand, PhD, RN, CCRN, College of Nursing, Brigham Young University, 422 SWKT, PO Box 25432, Provo, UT 84602-5432; E-mail: renea@byu.edu.

J Emerg Nurs 2017;43:40-8.

Available online 26 September 2015

0099-1767

Copyright (@) 2017 Emergency Nurses Association. Published by Elsevier Inc. http://dx.doi.org/10.1016/j.jen.2015.08.017 becomes even more complicated in the chaotic environment of the emergency department, where quality EOL care is often overshadowed by resuscitation efforts and emergency procedures.

According to data from the 2010 National Hospital Ambulatory Medical Care Survey, 240,000 patients died in emergency departments in the United States in 2010, representing a $72 \%$ increase in the number of ED deaths reported in $2007 .^{2}$ The increased rate of deaths was due to traumatic and chronic causes. ${ }^{3}$ An increase in ED deaths of this magnitude stands to place even more burden on already strained emergency nurses.

In the past decade, considerable efforts have been made to understand the obstacles that prevented emergency nurses from providing high-quality EOL care. Emergency nurses have reported many obstacles to providing optimal EOL care, including poor ED design, lack of adequate privacy, inadequate palliative care training, and family issues. ${ }^{4-6}$ Although these reports have played an important role in understanding the obstacles to providing EOL care in emergency departments, all have been national random samples and thus have focused primarily on urban populations without specifically considering rural ED counterparts.

Rural populations can present unique complications in all aspects of health care. To understand the specific EOL care obstacles faced by rural emergency nurses, a literature search was conducted. Search terms were "rural," 
"emergency department," and "end-of-life." CINAHL, MEDLINE, and PsychINFO were the databases included in the query. The search returned a single article on the obstacles noted in caring for dying rural ED patients. ${ }^{7} \mathrm{~A}$ separate search of the databases for emergency nurses' EOL stories returned no pertinent results. The minimal published research on rural emergency nursing demonstrates a need for increased understanding of the obstacles to EOL care in rural emergency departments. This study will report the first-person experiences or stories of rural emergency nurses who have cared for dying patients and the obstacles these nurses encountered while attempting to provide EOL care.

The research question for this study was, "What are the shared experiences (stories) that epitomize obstacles to providing EOL care to dying patients in rural emergency departments?" Rural emergency nurses were asked to respond to the following open-ended question: "Can you share with us an experience you have had when caring for a dying patient in a rural setting that epitomizes the obstacles to providing EOL care in this setting?"

\section{Methods}

\section{STUDY DESIGN}

This study was conducted as a cross-sectional mailed survey sent to rural emergency departments selected from a convenience sample of 5 states with high proportions of designated rural areas as defined by the presence of critical access hospitals (CAHs).

\section{DATA COLLECTION INSTRUMENT}

Qualitative data for this report were collected using the Rural Emergency Nurses' Perception of End-of-Life Care questionnaire. This rural questionnaire was adapted from a previous EOL questionnaire used to conduct research with a national random sample of emergency nurses who mostly worked in urban areas. ${ }^{8}$ The rural adaptation was designed to measure rural emergency nurses' perceptions of the size and frequency of EOL care obstacles and to allow rural nurses to share personal experiences/stories and recommendations in a free response format. ${ }^{8,9}$

The Rural Emergency Nurses' Perception of Endof-Life Care questionnaire was composed of 39 Likert-type questions, 3 open-ended questions, and 15 demographic questions. The instrument was pretested by 15 rural emergency nurses from Utah. Nurses who were asked to complete the pretest instrument assessed the content of the questionnaire and helped to determine the average completion time, which was 25 minutes.

\section{SAMPLE AND SETTING}

The most rural areas in the United States by low population densities, according to the 2010 census data, are presented in Figure. ${ }^{7,10} \mathrm{CAH}$ emergency departments provide emergency service to rural communities; therefore, emergency nurses working in the emergency departments of $\mathrm{CAHs}$ were identified as being appropriate to provide information regarding rural emergency EOL care. Based on areas of rural population, a convenience sample of 4 states in the Intermountain West region plus the state of Alaska were chosen to participate because of their numbers of designated CAHs.

\section{STUDY PROCEDURES}

After obtaining Institutional Review Board approval, ED managers were contacted by phone for the 73 listed CAHs from the Intermountain West region (consisting of Idaho, Nevada, Utah, and Wyoming) and Alaska. If the managers were unavailable or did not answer, detailed messages were left requesting study participation. Contact was attempted up to 4 times. If the manager agreed to distribute the study questionnaires, he or she was sent the appropriate number of questionnaire packets, each containing an explanation of the study in the form of a cover letter, a questionnaire, a self-addressed stamped return envelope, and a $\$ 1$ bill attached to each questionnaire to thank the nurse for participating in the study. Managers were asked to distribute questionnaire packets to emergency nurses in their departments with no obligation to participate. The return of a completed questionnaire was considered consent to participate.

Contact was made with 56 of the $73 \mathrm{CAH}$ ED managers, and $53(94.6 \%)$ agreed to participate in the study (see Table 1 for return by state). A total of 508 questionnaire packets were mailed. Completed and returned questionnaires totaled 246, for a response rate of $46.4 \%$. The respondents were primarily registered nurses (RNs) but also included 5 licensed practical nurses and 3 paramedics. Responses of non-RNs were not included in this data analysis.

Inclusion criteria consisted of the ability to read English, having worked in a rural emergency department, and a history of providing care for at least one dying rural ED patient. All responses were entered into a Word database.

\section{DATA ANALYSIS}

Five nursing experts including an experienced researcher, a qualitative researcher, an advance practice nurse researcher, an advance practice nurse with 11 years of ED experience, and a graduate student individually reviewed and coded 


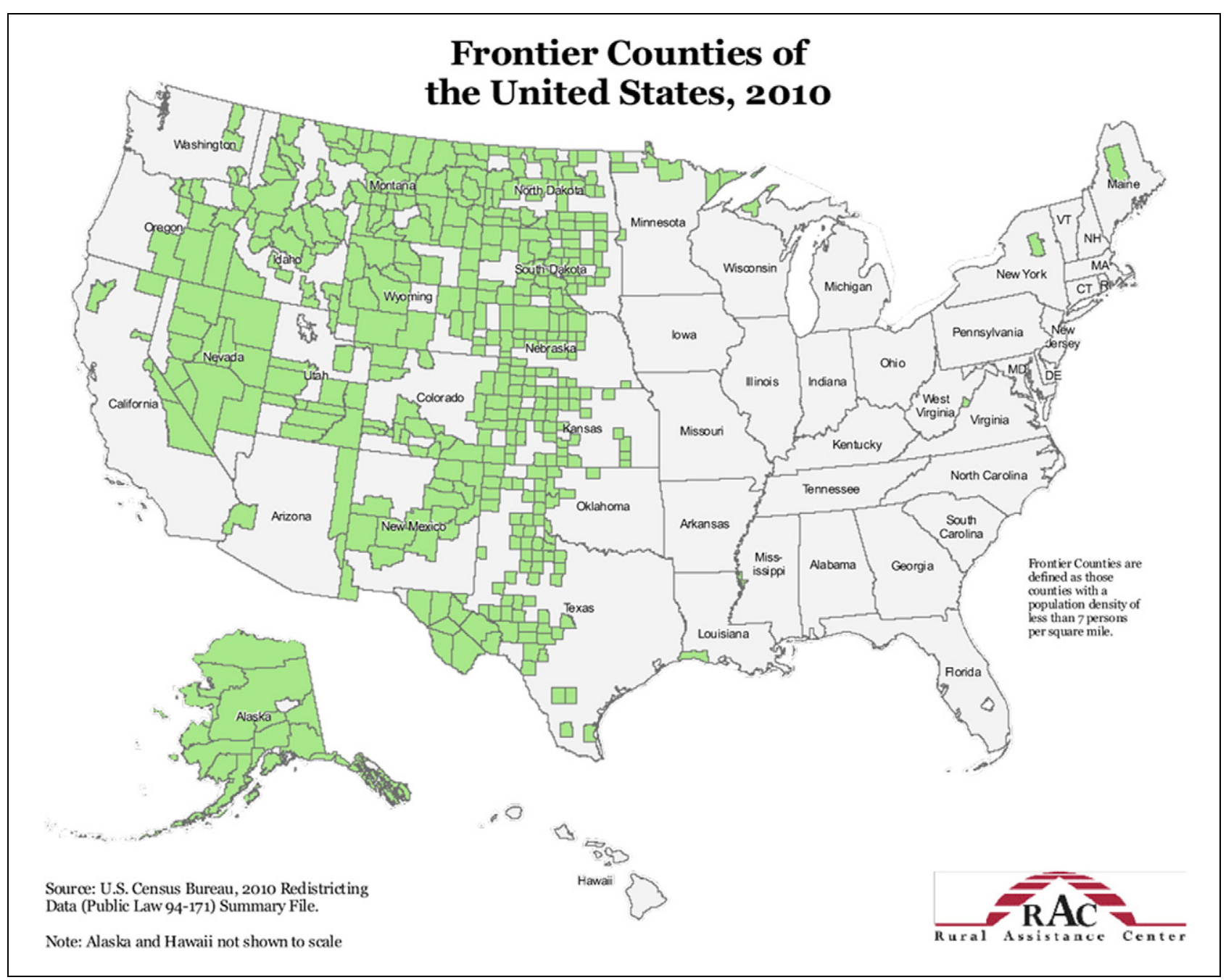

FIGURE

Frontier counties of the United States, 2010.

TABLE 1

\section{Questionnaires returned by state}

\section{State}

Questionnaires returned, $\mathbf{n}(\%)$

$\begin{array}{lr}\text { Idaho } & 113(47.5) \\ \text { Wyoming } & 57(23.9) \\ \text { Utah } & 29(12.2) \\ \text { Nevada } & 21(8.8) \\ \text { Alaska } & 18(7.6) \\ \text { Total } & 238(100)\end{array}$

each response using content analysis. Content analysis, as a data analysis method, is used on data collected through documents and then analyzed using interpretive coding to arrive at themes. ${ }^{11}$ During the first round of analysis, all data were coded individually for themes. In the second round of analysis, the research team collectively identified the themes and story frequencies of all eligible data.

Of the 246 questionnaires returned, 107 nurses responded to the question, "Can you share with us an experience you have had when caring for a dying patient in a rural setting that epitomizes the obstacles to providing EOL care in this setting?" Responses were initially reviewed to 
TABLE 2

Demographics $(\mathrm{n}=27)$

Characteristic

n

$\%$

M

SD

Range

Sex

Female

Male

24

3

Age, y

Years as registered nurse

Years in emergency department

Years in rural nursing

Beds in emergency department

No. of dying patients cared for

$$
>30
$$

21-30

$11-20$

5-10

$<5$

Highest degree, \%

Diploma

Associate

Bachelor

Master

Other

Ever certified as CEN

Yes

No

Currently CEN

Yes

No

Years as CEN

Practice area

Direct care/bedside nurse

Staff/charge nurse

Clinical nurse specialist

Other (eg, manager or educator)

\section{4}

20

3

3
11.5

70.4

18.5

0.04

0

16

80

14.8

30

14.8

0.0

0.04

8.5

(

Hospital type

Community, nonprofit

Community, profit

County hospital

Other

8

88.9

1.1

46

9.5

63-27

15.4

10.6

2-39

11.8

8.1

1.5-36

11.6

8.1

2-36

5.3

2.8

8


TABLE 3

Frequency of perceived obstacles to providing endof-life care

\begin{tabular}{lll} 
Obstacle themes & Frequency rank & $\mathbf{n}^{\mathbf{a}}$ \\
\hline Lack of ideal death & 1 & 13 \\
Insufficient staffing & 2 & 9 \\
Power struggles & 3 & 9 \\
Chaotic/overwhelming environment & 4 & 8 \\
Staff relationship to patient & 5 & 5 \\
Ignoring patient's wishes & 6 & 4 \\
Lack of family involvement & 7 & 3 \\
ED design & 8 & 2 \\
Futility of efforts & 9 & 1
\end{tabular}

a Stories often contained several themes.

missing, and thus they were not analyzed for this report. After individual coding was completed, researchers met to analyze and determine common themes. Any disagreements in coding were discussed until consensus was achieved.

\section{Results}

Twenty-seven nurses $(25.2 \%)$ responded in an appropriate format for consideration as an EOL obstacle story. One participant responded with 2 distinct EOL obstacle stories for a total of 28 story responses. Of the total respondents, $24(88.9 \%)$ were women and $3(11.1 \%)$ were men. The average age of the participants was 46 (standard deviation $[S D]=9.5)$ years. Participants had an average of $15.4(S D=$ 10.6) years of $\mathrm{RN}$ experience and $11.6(\mathrm{SD}=8.1)$ years of experience in a rural emergency department. Other demographic data are displayed in Table 2.

Content analysis revealed 3 predominant themes, with each theme representing an obstacle to providing quality EOL care that was present in the rural emergency nurses' stories. The most common obstacle themes were (1) the lack of an ideal death for the patient, (2) insufficient ED staff to provide quality EOL care, and (3) power struggles between emergency nurses, physicians, and patients' families. Various other obstacle themes were also represented, but less frequently. Stories often included several themes (see Table 3).

\section{LACK OF AN IDEAL DEATH}

The most commonly identified obstacle theme $(n=13$, 46.4\%) was the absence of what the nurse considered to be an "ideal" or good death for the patient and the patient's family. Each nurse's story, specific to this theme, demonstrated different obstacles, ranging from caring for dying patients or family members known to the nurse, to difficulties with family involvement, to not knowing the patient's EOL care wishes.

\section{Rural Emergency Nurses Provide EOL Care for People They Know}

One particularly striking story related by a nurse told of the hardship of caring for a trauma victim who was also her friend:

[A] co-worker (nurse) was involved in [a head injury] trauma. I did not know who the patient was until I saw the ring on her finger (wedding ring) and recognized it belonged to my friend. I then looked up and saw her husband sitting in a chair covered with blood. He had been doing CPR prior to [the] ambulance arrival. We coded her for an hour. The first half hour of her ER time I was unaware [that] this was my friend. [When] I did recognize her ring and her husband, I had a hard time refocusing. [There was] no time to call in clergy prior to death, [and] no social worker on staff at our hospital.

Another rural emergency nurse contributed this graphic story about providing EOL care to the dying family member of a coworker:

We had a victim of a trauma brought in by his distraught family, one of which was his sister-in-law [who was] one of our emergency nurses. There was a ton of family there and we didn't have the heart to ask them to leave. One brother became very anxious and had to also be seen by the MD and given a sedative. It was very chaotic. All efforts were made to save this young man but it was futile. I felt I was suctioning parts of his brain out through his mouth because it filled up as fast as I suctioned him but still all these heroic efforts were continued till he was warm and dead.

As these 2 stories shared by rural emergency nurses demonstrate, providing EOL care for known patients or families can be a tremendous obstacle. Families can also be an obstacle even when they are not known to the emergency nurse.

\section{Families as Obstacles to Providing Rural EOL Care}

Regarding the obstacle of difficulties with families, one rural emergency nurse shared the following story about how family issues impeded her attempt to provide quality EOL care.

[A] mother was dying - she had 10 children. Living will and advanced directives [were] in place. The patient is showing true signs and symptoms of shutting down. 
The eldest siblings are okay with following Mom's advance directives, but not some of the younger...they proceeded to take their verbal disagreement out in the hospital halls, yelling loudly. Physician was notified, but didn't want to come in, left it to me to tell family that he will not change current care until all family members agreed....

Another rural emergency nurse told this story about the emotional difficulty of providing EOL care in the presence of grieving family members: "We let family come into the trauma room and having her lay across the patient yelling at him to not die, 'Don't leave me,' was very hard on everyone."

Issues with families were important obstacles to providing EOL care in rural emergency departments. Another obstacle impeding good EOL care was when the patient's wishes for care were unknown.

\section{EOL Care When the Patient's Wishes Are Unknown}

An emergency nurse shared the following story about obstacles faced when trying to provide an elderly patient with a peaceful or good death.

[An] elderly woman came in with a quick response unit as a full code. We worked on the patient for approximately 45 minutes before the doctor called it. [Then] the patient started to breath agonally and the doctor stated not to resume CPR. [We] put the patient behind curtains and had pain meds on hand. It was [then] discovered that the patient was do not resuscitate (DNR). It took several minutes for the patient to die, and we were unable to get a hold of any family.

Whereas these 5 stories provided examples of rural emergency nurses being unable to provide dying patients with a good death due to issues with knowing the patient, family difficulties, or unknown patient wishes, stories of obstacles related to insufficient staff were also frequently reported.

\section{INSUFFICIENT ED STAFF}

The second most commonly identified theme by the rural emergency nurses was the lack of sufficient staff $(\mathrm{n}=9$, $32.1 \%)$. One rural emergency nurse shared this story about a rural emergency department/hospital where a patient died unattended without immediately being noticed by the nursing staff: "Pt. [at] EOL on [unit] with family visiting. ER full, nurse in ER, family left, new family member on their way down the hall. X-ray tech noticed pt. deceased, notified nurse. Nurse made it to the room [just] prior to the family member."
This story highlights staffing issues and the dual responsibilities of rural emergency nurses who may be required to care for admitted patients in addition to patients entering through the emergency department. Not only did this patient face his or her last moments alone, but there was also no nurse present to ensure that EOL care, pain, and comfort goals were being met as the patient died.

Another nurse reported how a busy and understaffed emergency department also led to poor EOL care:

A patient was in a very bad accident. We treated an aunt; grandmother; and the semi-truck driver... It was hard to give [them] EOL care. We also had a patient at the same time that wrecked a motorcycle with a broken ankle and no pedal pulses. We were so busy. The floor also had 5 inpatients. There was too much for 3 nurses to handle. The dying aunt and grandmother's EOL cares [were] neglected. The niece who was traveling with them needed a lot of emotional support that we didn't have time to give her.

While staffing concerns did include a shortage of nurses, the concerns also embodied a deficit of help from social support staff in this critical situation. For example, another rural emergency nurse shared this story about her trying attempt to provide EOL care for an infant without the help of support staff:

[There was an] 18-month-old SIDS [sudden infant death syndrome] patient brought to hospital by ambulance. Family was pretty much left alone for some time with child to say goodbye. We did not have any type of social service, counseling, or religious assistance. As the nurse, I did my best to check on them and provide emotional support, but I had no training or previous experience with a dying child.

In addition to inadequate staffing and EOL training, the final major theme reflecting rural EOL care obstacles encompassed issues of nurses feeling powerless to help dying patients.

\section{POWER STRUGGLES}

Disagreements between members of the health care team, as well as disagreements between the team and a patient's family, were common occurrences in many rural emergency departments. One nurse related an account of how a power struggle between a physician, nurse, and patient's family led to poor EOL care for an especially vulnerable patient:

[A patient] was middle-aged and profoundly retarded. [Patient] had pacer discontinued 2 days prior to admission and sole parent had executed DNR. [The] patient went into arrest. Parent came to ER and provider persuaded parent that a chance of resuscitation was good. Pt. had been down greater 
than 30 minutes. Provider [then] used patient as practice for intubation, central line, and defibrillation.

Sadly, this experience represents an example of unethical behavior toward a vulnerable dying patient where the nurse felt powerless to intercede. Unfortunately, current medical hierarchy often prevents nurses from having the opportunity to speak up and be a part of the decision-making process at the end of life.

\section{OTHER OBSTACLES}

In addition to the aforementioned themes, other stories demonstrated several additional obstacle themes ranging from lack of EOL care training to problems with ED design, mostly regarding the lack of privacy for the dying patient and his or her grieving family. Rural emergency nurses also expressed concern about the sense of futility they felt while caring for dying patients. Although these obstacles occurred less frequently, they did represent momentous hurdles to the provision of quality EOL care, as well as areas of stress and concern for the rural emergency nurses.

\section{Discussion}

Not being able to provide a good or ideal death was identified as the most significant obstacle theme. For this major theme, 3 subheadings emerged: (1) rural emergency nurses providing care to known patients, (2) families as obstacles to EOL care, and (3) unknown EOL care wishes. The inability to overcome these obstacles and provide the patient with an ideal death frequently appeared to be a cause of stress and regret for rural emergency nurses.

Rural emergency nurses are often required to provide EOL care to friends and family members, while their urban counterparts are more likely to have the option to transfer care to nurses with no relation to the dying patient. Not only does caring for patients that the nurse knows or is related to cause great distress to rural emergency nurses, this unfortunately common situation may also prevent patients from receiving the highest quality of EOL care.

A 2010 study by Beckstrand et $\mathrm{al}^{7}$ ranked "knowing the patient or family members personally" as the second-largest obstacle faced by rural emergency nurses in their provision of quality EOL care. Previous studies that have not specifically examined rural emergency departments do not list knowing the patient as an obstacle to providing EOL care in the emergency department. ${ }^{5,8,9}$ This previous research supports the idea that knowing the patient is an obstacle that is largely unique to rural emergency nurses.
In concert with knowing the patient, problems with the patient's family often prevented an ideal or good death. The problems with families included both too much and too little involvement in EOL care. One nurse was forced to become a mediator during a heated family dispute, while another was unable to obtain information she needed to provide EOL care because the patient's family left the emergency department suddenly. The original study on rural ED EOL care obstacles included problems with families as 5 of the top 10 obstacles. These problems ranged from "families who continually call" to "dealing with angry family members." 7 Problems caused by family members also rank highly as obstacles to EOL care in nonrural emergency departments. ${ }^{8,9}$

The final minor theme in this area involved the nurse being unable to ascertain if the patient had specific EOL care wishes. One story highlighted the challenges faced by emergency nurses when an elderly patient entered the emergency department with no family and minimal accompanying information, thus preventing staff from verifying the patient's code status or contacting family members before the patient died. Although this obstacle played an important role in rural emergency nurses' stories, they ranked it as the thirteenth most significant obstacle to EOL care in the original study. ${ }^{7}$

Rural emergency nurses identified insufficient ED staff as another significant obstacle to providing quality EOL care. The nurses' stories epitomized the difficult task faced by nurses in rural emergency departments as staffing concerns compelled them to take on roles outside their level of training and experience in an attempt to afford comfort to dying patients and their families. Previous studies rated similar obstacles very highly. Beckstrand et $\mathrm{al}^{7}$ reported "Patient care being fragmented in the rural emergency department because the nurse is required to fill many roles other than nursing" and "The nurse having too high a workload" as the fifth and fourteenth highest obstacles, respectively. ${ }^{7}$

Power struggles between physicians and nurses have been an ongoing theme in hospital-based health care. These struggles often lead to nurses being unsatisfied with the level of input they are afforded and feeling as if they are not valued. ${ }^{13}$ It is no surprise that rural emergency nurses also experienced nurse-physician power struggles and believed that it was an important obstacle to providing good EOL care in their setting. In the chaotic environment of the emergency department, such disagreements have the potential to degrade the quality of the EOL care being provided by the ED staff. In addition to power struggles with physicians, rural emergency nurses also shared stories about disagreements with patient family members. Family 
members requesting that staff ignore patient wishes or continue heroic measures against advice were represented multiple times in the rural emergency nurses' stories.

Few studies specifically examine the obstacles faced by rural emergency nurses in their provision of EOL care. Many of the obstacles identified here in the nurses' stories were also represented in the original study with similar levels of frequency. ${ }^{7}$ Our results also correspond closely with the obstacles identified in other quantitative nonrural ED studies of the same nature. ${ }^{8,9}$ No studies examining nurses' EOL care experiences in story format were available for comparison.

In contrast with the quantitative report on rural EOL care, ${ }^{7}$ the nurses' stories in the current study displayed some different obstacle themes. The inability to provide the patient with what the nurse considered to be an ideal death is a subject that has not been discussed in previous research. Lack of an ideal death also appears to be an area of significant distress for many nurses and represents the culmination of several other smaller obstacles.

The open-ended question from the Rural Emergency Nurses' Perception of End-of-Life Care used in this study was designed to give nurses a forum to express their experiences of the obstacles they face when caring for dying patients. We found that rural emergency nurses' experiences with death are multifaceted and are often far from what might be considered ideal. The obstacles rural emergency nurses face have lasting consequences not only for patients and families but for the nurses as well.

\section{Limitations}

A limitation of this study is that it used a convenience sample of states with high proportions of CAHs instead of a randomly selected sample of states. Nurses' stories were personal and may not be representative of all rural emergency nurses' experiences and therefore are not generalizable to all rural emergency nurses.

\section{Implications for Emergency Nurses}

Rural emergency nurses' experiences of EOL care obstacles have commonalities across state lines. Understanding the experiences of rural emergency nurses in their quest to provide quality EOL care will lay the ground work for further research and may help provide the basis for systemic changes that remove the EOL care obstacles faced by nurses on the frontier of emergency health care. This report should alert rural hospital and ED administrations about the needs of rural emergency nurses (such as increased staff availability and the need for support help from persons such as social workers) as nurses care for dying patients and their families. Educating rural emergency nurses in EOL care should also be a priority.

\section{Conclusion}

Nurses in the emergency department care for dying patients daily. Emergency nurses often face obstacles that hinder their ability to provide high-quality EOL care to patients. These obstacles are frequently compounded by the unique set of challenges faced by nurses working in rural emergency departments. Stories from rural emergency nurses revealed that being unable to provide optimal care at the EOL, having difficulties with family members, or not knowing the patient's wishes for EOL care were the most common obstacles. Additional obstacles included stories about the impact of low staffing or unavailable staff and feeling powerless in some EOL situations. It is clear that rural emergency nursing remains a frontier area for health care and warrants continued research. A greater understanding of the obstacles faced by rural emergency nurses may allow changes to be implemented that can improve the quality of EOL care for patients and improve nurses' quality of life and job satisfaction.

\section{Acknowledgments}

We thank Virginia Giles, FNP, for her assistance in obtaining the sample of rural emergency nurses and Lynette Jakins for her help in her role as College of Nursing Research Secretary.

\section{REFERENCES}

1. Peters L, Cant R, Payne S, et al. Emergency and palliative care nurses' levels of anxiety about death and coping with death: a questionnaire survey. Australas Emerg Nurs J. 2013;16:152-159.

2. Niska R, Bhuiya F, Xu J. National hospital ambulatory medical care survey: 2010 emergency department summary. http://www.cdc.gov/ nchs/data/ahcd/nhamcs_emergency/2010_ed_web_tables.pdf. Accessed September 4, 2015.

3. Niska R, Bhuiya F, Xu J. National hospital ambulatory medical care survey: 2007 emergency department summary. http://www.cdc.gov/ nchs/data/nhsr/nhsr026.pdf. Published August 6, 2010. Accessed September 4, 2015.

4. Bailey CJ, Murphy R, Porock D. Dying cases in emergency places: caring for the dying in emergency departments. Soc Sci Med. 2011;73:1371-1377. 
5. Beckstrand RL, Wood D, Callister LC, Luthy KE, Heaston S. Emergency nurses' suggestions for improving end-of-life care obstacles. J Emerg Nurs. 2012;38(5):7-14.

6. Norton CK, Hobson G, Kulm E. Palliative and end-of-life care in the emergency department: guidelines for nurses. J Emerg Nurs. 2011;37(3):240-245.

7. Beckstrand RL, Giles VC, Luthy KE, Callister LC, Heaston S. The last frontier: rural emergency nurses' perceptions of end-of-life care obstacles. J Emerg Nurs. 2012;38:15-25.

8. Heaston S, Beckstrand RL, Bond AE, Palmer S. Emergency nurses' perceptions of obstacles and supportive behaviors in end-of-life care. J Emerg Nurs. 2006;32(6):477-485.

9. Beckstrand RL, Smith MD, Heaston S, Bond AE. Emergency nurses' perceptions of size, frequency, and magnitude of obstacles and supportive behaviors in end-of-life care. I Emerg Nurs. 2008;34(4):290-300.

10. Rural Assistance Center. CAH frequently asked questions. http://www. raconline.org/topics/hospitals/cahfaq.php\#whatis. Accessed September 5, 2015 .

11. Houser J. Qualitative research questions and procedures. Nursing Research: Reading, Using, and Creating Evidence. 3rd ed. Sudbury, MA: Jones \& Bartlett Learning; 2015.

12. Merriam-Webster Dictionary. Story. http://www.merriam-webster.com/ dictionary/story. Accessed September 4, 2015.

13. Coombs M, Ersser SJ. Medical hegemony in decision-making-a barrier to interdisciplinary working in intensive care? $J$ Adv Nurs. 2004;46(3):245-252. 